\title{
Interface Properties of Atomic-Layer-Deposited
}

\section{$\mathrm{Al}_{2} \mathrm{O}_{3}$ Thin Films on Ultraviolet/Ozone-Treated}

\section{Multilayer $\mathrm{MoS}_{2}$ Crystals}

Seonyoung Park, ${ }^{\dagger}$ Seong Yeoul Kim, ${ }^{\dagger}$ Yura Choi,,$^{\dagger}$ Myungjun Kim, ${ }^{\star}$ Hyunjung Shin, ${ }^{\ddagger}$ Jiyoung

Kim, ${ }^{\S}$ Woong Choi ${ }^{\dagger} *$

${ }^{\dagger}$ School of Advanced Materials Engineering, Kookmin University, Seoul 02707, Korea

${ }^{\star}$ Department of Energy Science, Sungkyunkwan University, Suwon 16419, Korea

${ }^{\S}$ Department of Materials Science and Engineering, University of Texas at Dallas, Richardson, Texas 75080, USA

\section{Corresponding Author}

*E-mail: woongchoi@kookmin.ac.kr 
1. Calculation of surface energy

Table S1. Contact angles and surface energy values calculated based on Wu model (harmonic mean) for the different surface treatments.

\begin{tabular}{|c|c|c|c|c|c|}
\hline $\begin{array}{c}\text { UV/O } 3 \text { exposure } \\
(\text { minute })\end{array}$ & $\theta_{\text {water }}$ & $\theta_{\text {DI }}$ & $\gamma_{\text {polar }}$ & $\gamma_{\text {dispersive }}$ & $\gamma_{\text {total }}$ \\
\hline 0 & 78.99 & 46.05 & 37.3 & 9.4 & 46.7 \\
\hline 1 & 60.36 & 42.31 & 39.1 & 17.8 & 56.9 \\
\hline 2 & 42.53 & 35.38 & 42.2 & 26.0 & 68.2 \\
\hline 3 & 12.65 & 29.63 & 44.6 & 36.6 & 81.2 \\
\hline 4 & 0 & 23.90 & 46.6 & 37.3 & 83.9 \\
\hline
\end{tabular}

The measured contact angle values $\theta$ were input into $\mathrm{Wu}$ model (harmonic mean) to calculate the polar $\left(\gamma^{\mathrm{p}}\right)$ and dispersive $\left(\gamma^{\mathrm{d}}\right)$ components of the total surface energy $\gamma^{\text {tot }}$, according to the following formula, were $\mathrm{W}$ refers to water and DI to diiodomethane:

$$
\begin{aligned}
& \gamma_{\mathrm{W}}\left(1+\cos \theta_{\mathrm{w}}\right)=\frac{4 \gamma_{\mathrm{W}}^{\mathrm{d}} \gamma^{\mathrm{d}}}{\gamma_{\mathrm{W}}^{\mathrm{d}}+\gamma^{\mathrm{d}}}+\frac{4 \gamma_{\mathrm{W}}^{\mathrm{p}} \gamma^{\mathrm{p}}}{\gamma_{\mathrm{W}}^{\mathrm{p}}+\gamma^{\mathrm{p}}} \\
& \gamma_{\mathrm{DI}}\left(1+\cos \theta_{D I}\right)=\frac{4 \gamma_{\mathrm{DI}}^{\mathrm{d}} \gamma^{\mathrm{d}}}{\gamma_{\mathrm{DI}}^{\mathrm{d}}+\gamma^{\mathrm{d}}}+\frac{4 \gamma_{\mathrm{DI}}^{\mathrm{p}} \gamma^{\mathrm{p}}}{\gamma_{\mathrm{DI}}^{\mathrm{p}}+\gamma^{\mathrm{p}}}
\end{aligned}
$$

The total surface energy is:

$\gamma^{\text {tot }}=\gamma^{\mathrm{d}}+\gamma^{\mathrm{p}}$ 
2. Calculation of electron density

We first converted the high-frequency $C$ - $V$ curve into a $1 / C^{2}-V$ curve shown in Figure S1. The electron density $N$ in $\mathrm{MoS}_{2}$ is obtained by inputting the slope $d\left(1 / C^{2}\right) / d V$, physical constants $q$ and $\varepsilon_{0}, \varepsilon_{\mathrm{s}}=4$, and $A=\pi\left(30 \times 10^{-4}\right)^{2} \mathrm{~cm}^{2}$ into the following equation.

$N(W)=2 /\left[q \varepsilon_{\mathrm{s}} \varepsilon_{0} A^{2} d\left(1 / C^{2}\right) / d(V)\right]$

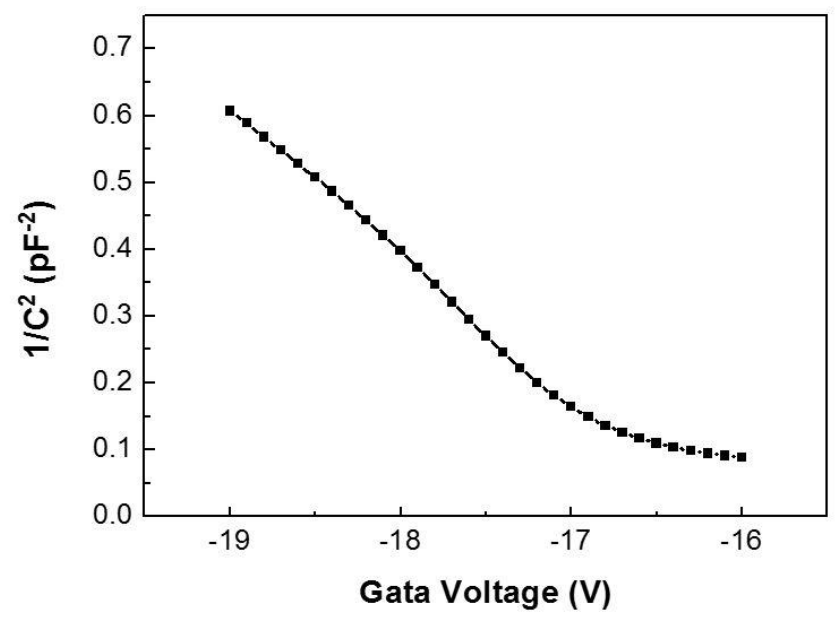

Figure S1. Calculated $1 / C^{2}$ as a function of gate voltage.

The distance $W$ at which the electron density $N$ is evaluated is obtained from: $W=\varepsilon_{\mathrm{s}} \varepsilon_{0} A\left(1 / C-1 / C_{o x}\right)$.

3. Calculation of interface trap density

The interface trap density is obtained by:

$D_{i t}=\left(C_{o x} / q\right)\left\{\left(C_{L F} / C_{o x}\right) /\left[1-\left(C_{L F} / C_{o x}\right)\right]-\left(C_{H F} / C_{o x}\right) /\left[1-\left(C_{H F} / C_{o x}\right)\right]\right\}$.

To obtain low-frequency capacitance value $C_{L F}$, we used the following fitted curve shown in Figure S2. 


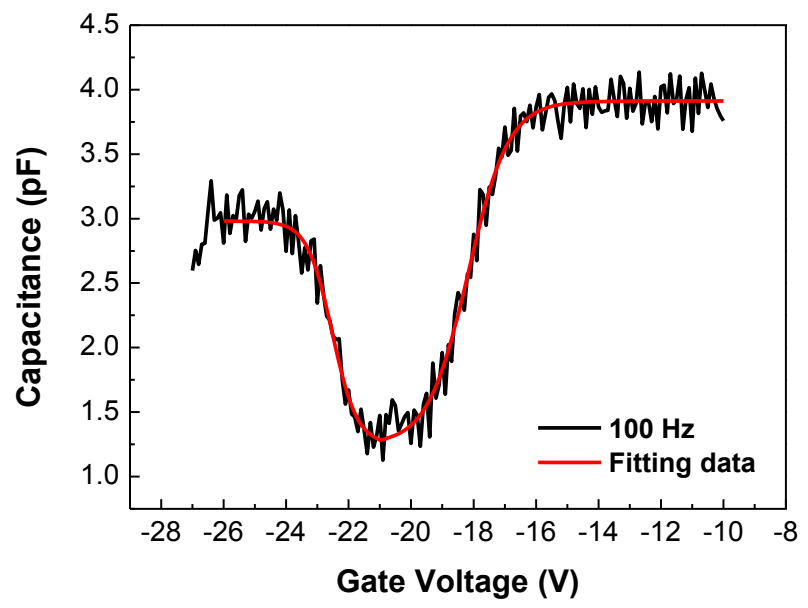

Figure S2. Measured and fitted low-frequency $C$ - $V$ curve.

\section{4. $\mathrm{Al}_{2} \mathrm{O}_{3}$-encapsulated bottom-gated $\mathrm{MoS}_{2}$ TFTs}

We also fabricated bottom-gated $\mathrm{MoS}_{2}$ TFTs with $\mathrm{ALD} \mathrm{Al}_{2} \mathrm{O}_{3}$ encapsulation layer (Figure S3). Multilayer $\mathrm{MoS}_{2}$ flakes were mechanically exfoliated from natural crystals (2D

Semiconductors) and transferred on a highly-doped p-type Si wafer with a thermally grown $\mathrm{SiO}_{2}$ layer $(300 \mathrm{~nm})$. Electrical contacts $(100 \mu \mathrm{m} \times 100 \mu \mathrm{m})$ were patterned on top of $\mathrm{MoS}_{2}$ flakes using conventional photolithography and lift-off technique. Ti (10 nm) and $\mathrm{Au}(100$ $\mathrm{nm}$ ) was deposited by electron-beam evaporation at room temperature. The device was then annealed at $400^{\circ} \mathrm{C}$ in a vacuum tube furnace for 2 hours $\left(100 \mathrm{sccm}\right.$ Ar and $\left.10 \mathrm{sccm} \mathrm{H}_{2}\right)$. The $\mathrm{Al}_{2} \mathrm{O}_{3}$ layer $(50 \mathrm{~nm})$ was deposited using TMA/water precursors in a custom-built thermal ALD system. An $\mathrm{Al}_{2} \mathrm{O}_{3}$ deposition cycle consisted of a series of alternating precursor and purging gas injections for different durations in a reliable ALD regime $\left(\mathrm{TMA} / \mathrm{N}_{2} / \mathrm{H}_{2} \mathrm{O} / \mathrm{N}_{2}\right.$ injections for 0.2/10/0.2/10 s). Electrical characterizations were carried out with I-V measurements (Keithley, Semiconductor Characterization System 4200-SCS) in vacuum before and after ALD processes. For a representative TFT, we compared the transfer curve of the TFT before and after $\mathrm{Al}_{2} \mathrm{O}_{3}$ encapsulation (Figure $\mathrm{S} 4$ ). 

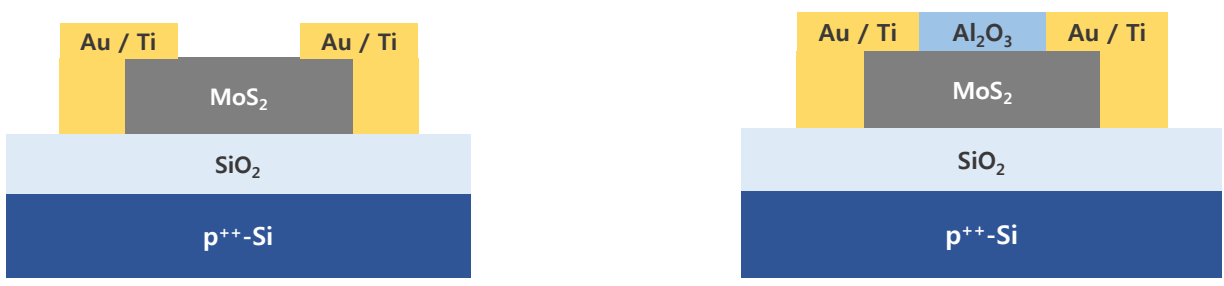

Figure S3. Schematic cross-sections of a bottom-gated $\mathrm{MoS}_{2}$ TFT before (left) and after (right) $\mathrm{ALD} \mathrm{Al}_{2} \mathrm{O}_{3}$ encapsulation
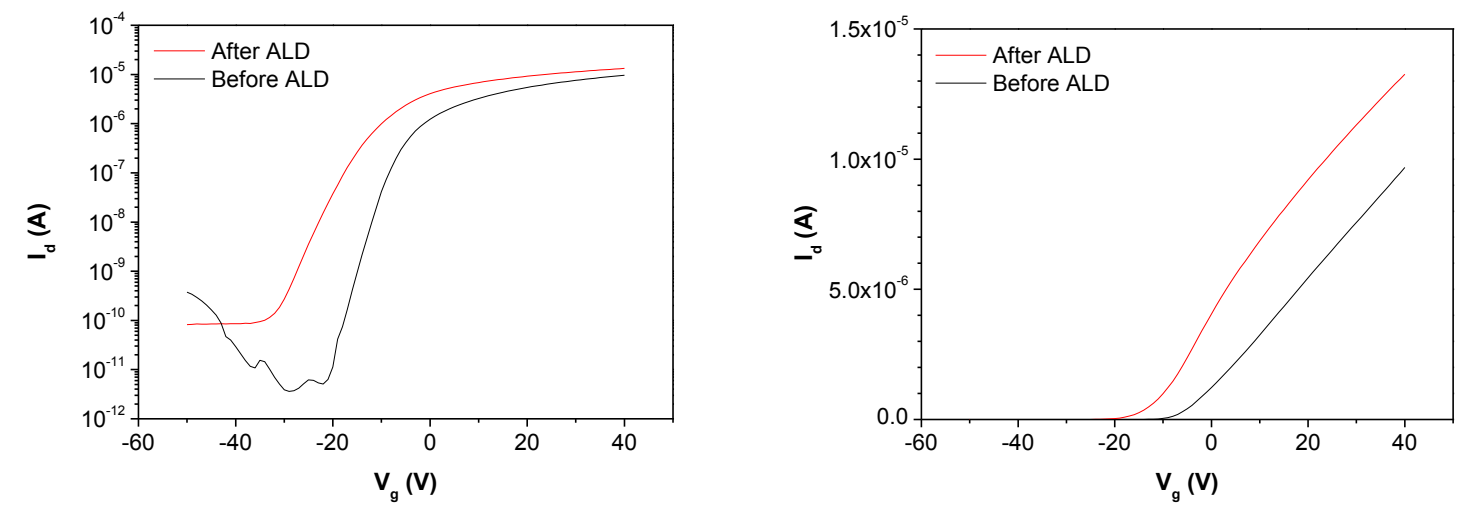

Figure S4. Transfer curves of a bottom-gated $\mathrm{MoS}_{2}$ TFT before and after ALD encapsulation (left: log-scale, right: linear-scale)

Table S2. Comparison of device performance metrics before and after ALD encapsulation

\begin{tabular}{|c|c|c|}
\hline & Before ALD encapsulation & After ALD encapsulation \\
\hline Field-effect mobility & $55.7 \mathrm{~cm}^{2} \mathrm{~V}^{-1} \mathrm{~s}^{-1}$ & $84.7 \mathrm{~cm}^{2} \mathrm{~V}^{-1} \mathrm{~s}^{-1}$ \\
\hline On/off-current ratio & $10^{7}$ & $10^{6}$ \\
\hline Subthreshold swing & $0.63 \mathrm{~V} \mathrm{dec}^{-1}$ & $1.28 \mathrm{~V} \mathrm{dec}^{-1}$ \\
\hline $\begin{array}{c}\text { Interface trap } \\
\text { density at } \mathrm{MoS}_{2^{-}} \\
\mathrm{SiO}_{2} \text { interface (from } \\
\text { subthreshold swing) }\end{array}$ & $6.9 \times 10^{11} \mathrm{eV}^{-1} \mathrm{~cm}^{-2}$ & N/A \\
\hline Threshold voltage & $-5.4 \mathrm{~V}$ & $-12.0 \mathrm{~V}$ \\
\hline
\end{tabular}

The observed changes of device performance metrics after $\mathrm{Al}_{2} \mathrm{O}_{3}$ encapsulation listed in Table $\mathrm{S} 2$ can be understood by the formation of additional top-surface conduction channel due to 
the positive fixed charges in $\mathrm{ALD} \mathrm{Al}_{2} \mathrm{O}_{3}$ encapsulation layer. ${ }^{\mathrm{R} 1, \mathrm{R} 2} \mathrm{We}$ pay attention to subthreshold swing $(S S)$ as it allows us to estimate interface trap density $\left(D_{i t}\right)$ by: $D_{i t}=\left(C_{o x} / q\right)[(q / k T)(S S / \ln 10)-1]$, where $C_{o x}, q, k$, and $T$ are the capacitance per unit area, unit charge, Boltzmann constant, and temperature, respectively. ${ }^{\mathrm{R} 3}$ As the deposition of an $\mathrm{Al}_{2} \mathrm{O}_{3}$ encapsulation layer does not significantly influence the bottom $\mathrm{MoS}_{2}-\mathrm{SiO}_{2}$ interface, ${ }^{\mathrm{R} 1}$ the increased subthreshold swing is probably due to the higher $D_{i t}$ at the top $\mathrm{MoS}_{2}-\mathrm{Al}_{2} \mathrm{O}_{3}$ interface than that at the bottom $\mathrm{MoS}_{2-}$ $\mathrm{SiO}_{2}$ interface.

According to carrier number fluctuation model based on low-frequency noise measurement of $\mathrm{Al}_{2} \mathrm{O}_{3}$-encapsulated bottom-gate $\mathrm{MoS}_{2}$ TFTs, $D_{i t}$ at the top $\mathrm{MoS}_{2}-\mathrm{Al}_{2} \mathrm{O}_{3}$ interface $\left(\sim 10^{11} \mathrm{eV}^{-1}\right.$ $\mathrm{cm}^{-2}$ ) was higher by about an order of magnitude than that at the bottom $\mathrm{MoS}_{2}-\mathrm{SiO}_{2}$ interface $\left(\sim 10^{10} \mathrm{eV}^{-1} \mathrm{~cm}^{-2}\right)$. ${ }^{\mathrm{R} 1}$ Hence, we expect $D_{i t}$ at the top $\mathrm{MoS}_{2}-\mathrm{Al}_{2} \mathrm{O}_{3}$ interface to be $\sim 10^{12} \mathrm{eV}^{-1}$ $\mathrm{cm}^{-2}$ in our bottom-gated $\mathrm{MoS}_{2}$ TFT with $\mathrm{Al}_{2} \mathrm{O}_{3}$ encapsulation. (Unfortunately, we do not have an access to resources such as low-frequency noise measurement which can allow us to estimate $D_{i t}$ at the top $\mathrm{MoS}_{2}-\mathrm{Al}_{2} \mathrm{O}_{3}$ interface after ALD encapsulation.) Although this is higher than the minimum $D_{i t}$ that we estimated from the $C-V$ measurement of $\mathrm{Au}-\mathrm{Al}_{2} \mathrm{O}_{3}-\mathrm{MoS}_{2}$ MOS capacitors, it is still comparable with the $D_{i t}$ of $\mathrm{MoS}_{2}-\mathrm{Al}_{2} \mathrm{O}_{3}$ interface in literature $\left(2.6 \times 10^{11}-7.7 \times 10^{12} \mathrm{eV}^{-1} \mathrm{~cm}^{-2}\right)$ estimated from subthreshold swing. ${ }^{\mathrm{R} 4-\mathrm{R} 6}$

References

[R1] Na, J.; Joo, M.-K.; Shin, M.; Huh, J.; Kim, J.-S.; Piao, M.; Jin, J.-E.; Jang, H.-K.; Choi, H. J.; Shim, J. H.; Kim, G.-T. Low-frequency noise in multilayer $\mathrm{MoS}_{2}$ field-effect transistors: the effect of high-k passivation. Nanoscale 2014, 6, 433-441.

[R2] Li, T.; Wan, B.; Du, G.; Zhang, B.; Zeng, Z. Electrical performance of multilayer $\mathrm{MoS}_{2}$ transistors on high-k $\mathrm{Al}_{2} \mathrm{O}_{3}$ coated $\mathrm{Si}$ substrates. AIP Adv. 2015, 5, 057102.

[R3] Zou, X.; Wang, J.; Chiu, C.-H.; Wu, Y.; Xiao, X.; Jiang, C.; Wu, W.-W.; Mai, L.; Chen, T.; Li, J.; Ho, J. C.; Liao, L. Interface engineering for high-performance top-gated MoS2 field-effect transistors. Adv. Mater. 2014, 26, 6255-6261.

[R4] Kim, S.; Konar, A.; Hwang, W.-S.; Lee, J. H.; Lee, J.; Yang, J.; Jung, C.; Kim, H.; Yoo, J.-B.; Choi, J.-Y.; Jin, Y. W.; Lee, S. Y.; Jena, D.; Choi, W.; Kim, K. High-mobility and Low-power Thin-film Transistors Based on Multilayer $\mathrm{MoS}_{2}$ Crystals. Nat. Commun. 2012, 3, 1011. 
[R5] Liu, H.; Ye, P. D. $\mathrm{MoS}_{2}$ dual-gate MOSFET with atomic-layer-deposited $\mathrm{Al}_{2} \mathrm{O}_{3}$ as topgate dielectric. IEEE Electron Device Lett. 2012, 33, 546-548.

[R6] Choi, K.; Raza, S. R. A.; Lee, H. S.; Jeon, P. J.; Pezeshki, A.; Min, S. W.; Kim, J. S.; Yoon, W.; Ju, S.-Y.; Lee, K.; Im, S. Trap density probing on top-gate $\mathrm{MoS}_{2}$ nanosheet field-effect transistors by photo-excited charge collection spectroscopy. Nanoscale 2015, 7, 5617-5623. 